\title{
Economic Analysis of Different Broiler Farm Capacities: A Case Study of Jordan
}

\author{
Ali AL-Sharafat ${ }^{1} \&$ Torki Mejhim Al-fawwaz ${ }^{2}$ \\ ${ }^{1}$ Department of Agricultural Economics and Extension, Faculty of Agriculture, Jerash University, Jordan \\ ${ }^{2}$ Finance and Economic Department, Faculty of Finance and Business Administration, AL Al-bayt University, \\ Mafraq, Jordan \\ Correspondence: Torki M. Al-Fawwaz, Finance and Economic Department, Faculty of Finance and Business \\ Administration, AL Al-bayt University, Mafraq, P.O. Box 1117, 11947, Amman, Jordan. Tel: 962-77-671-4955. \\ E-mail: alfawwaz@aabu.edu.jo
}

Received: October 31, 2012

Accepted: January 21, 2013 Online Published: February 16, 2013

doi:10.5539/ijbm.v8n5p41

URL: http://dx.doi.org/10.5539/ijbm.v8n5p41

\begin{abstract}
In agribusiness, broiler farms capacity is considered to be a very important factor in determining the profitability of these farms in developing countries. The main objective of this study was to introduce a comparative analysis of different broiler farm capacities in Jordan to determine the best viable capacity to be adopted. A total of 21, 72, and 7 producers were interviewed representing small, medium, and large farms respectively. A structured questionnaire was designed to obtain information from respondents. The Net Present Value (NPV), the Internal Rate of Return (IRR) and the Benefits-Costs ratio (B/C) were the discounted financial indicators used to achieve the goals of the study. The results of the study revealed that all the financial indicators used were economically acceptable in the medium and large size broiler production capacities. The NPV for these two capacities was positive and acceptable (23437 and 55880 JDs respectively). The benefits of these two capacities outweighed the actual costs that went in the project. For small farms, the NPV value was negative indicating non viable type of business compared to the other two capacities. Each money unit invested in small farms will cause a loss of 12.8 units (IRR $=-12.8 \%$ ). On the other hand, each money unit invested in medium and large farms will provide returns higher of about $22 \%$ than the costs paid (IRR = almost $22 \%$ for both). The payback for these two capacities was 1.06 times the costs meaning that for every unit of cost the project will get 1.06 units of gain. Adoption of medium to large broiler farm capacities in Jordan is recommended by this study.
\end{abstract}

Keywords: broiler farms, comparative analysis, discounted financial indicators, farm capacity

\section{Introduction}

Compared to other agricultural sub-sectors, in the situation of enhancing agriculture industry meat farming sub-sector is with high potential (Iman and Reza, 2012). In poultry farms focused on meat production, broiler breeds are raised mainly in environmentally controlled poultry houses. Fertile eggs are collected and transported to the hatchery, where they are placed in hatcheries for 18 days and then transferred to incubators in the last 3 days .After hatching, broiler chicks are distributed to producers who grow out the birds, and send them for slaughtering and processing after 42 days. These broilers are chickens that are raised for the purpose of meat production and have a larger body frame and weight than layers (Beutler, 2007).

In addition to providing food to human beings, the poultry industry concentrates on providing employment not only to those engaged in production directly, but also for the hatchery operations, feed dealers, manufactures of incubators, building materials, processors of egg and poultry products, and all dealers engaged in the marketing process (Morly, 1982). Many factors may affect the production process in broiler production. The type of the production system is the major one. The intensive production system is a largely adopted production system which decrease prorates inputs per bird during the production period (Najafi et. al., 2012). The amount of production cannot be predicted with certainty by broiler producers because of weather conditions, disease causes, pests and other related factors. Other factors related to processing and marketing processes may also cause production losses (Barnett et al., 2005). High and fluctuate feed prices are other important obstacles in the development of broiler industry. Increasing broiler farm capacity to 25,000 broiler chickens will make the farming financially feasible (Firdaus, 2010). Bird stocks, operating costs, and other costs were important factors 
to broiler output. Age, education, family size, training and access to credit, were found to be technical inefficiencies of farmers' abilities that largely affecting production (Areerat et. al., 2012). Factors such as: feeding system, water quality and the type of ration among the managerial factors have noticed effect on broiler rearing operations (Esteghamati et. al., 2012).

Among other livestock sectors in Jordan, broiler production is one of the most important sectors. The protein supply gap could be narrowed through poultry meat which is produced in broiler farms. Compared to other sources of protein this supply is provided in minimum possible time. Among other Arab countries, the broiler industry in Jordan is one of the first five leading countries. In Jordan per capita broiler meat production is nearly $22 \mathrm{~kg}$ (Food and Agricultural Organization (FAO), 2008). In other Arab countries this figure ranges from 0.67-33.0. These figures give an idea about the position of Jordan among the Arab countries concerning broiler industry. In Jordan, about $85 \%$ of poultry farms practice broiler meat production. The country contains 28000 thousand broiler birds produced in 1909 broiler farms during the year 2010. Around 60\% of the agricultural production is provided by the livestock sector (Ministry of Agriculture, 2010). The total value of the livestock sector products in Jordan in the year 2011was approximately 820 million JD (Department of Statistics, 2011). One Jordanian Dinar equals about 1.4 United States Dollars. Almost fifty percent of this value was due to poultry production.

The financial indicators used to accomplish the objectives of this study included The Net Present Value (NPV), the Internal Rate of Return, and the Benefit Cost Ratio (b/c). These indicators provided reasonable and reliable tools to conduct a financial feasibility analysis as a procedure of economic analysis to achieve the goals of any financial feasibility study. The value of the initial investment subtracted from Present value of future net cash flows considered to be the NPV of an investment. The investment is to be made if the value of NPV is positive; otherwise, it should not (Lin et al., 2000).

Another important indicator used to help in judging whether to make investment or not is the Internal Rate of Return (IRR). The IRR is an efficiency indicator for any investment which gives a value to judge the investment (Bruce, 2003). When zero net present value of an investment is reached, the discount rate at that value is the IRR of that investment. At this point if the IRR is less than the costs it is necessary to avoid the investment (Baker, 2000).

The decisions in any business investment could be analyzed in the best manner using Benefits to Costs Analysis (BCA) (Bent et al., 2002). Also, the feasibility of many public investments could be investigated through BCA (Orth et al., 1998). In such public investments subtraction of costs from benefits is the core of BCA (Boardman et al., 2001). The relationship between the NPV, IRR and BCA could be fully understood if the fact that the associated costs and benefits expression is made using discounted present values (Ascott, 2006).

The main objective of this study is to introduce a comparative analysis of different broiler farm capacities in Jordan to determine the best viable capacity to be adopted. The analysis will be based on three discounted financial indicators. These include The Net Present Value (NPV), the Internal Rate of Return (IRR) and the Benefits-Costs ratio $(\mathrm{B} / \mathrm{C})$. Other associated economic issues will be investigated.

\section{Materials and Methods}

\subsection{The Sample}

According to the statistical formula used in this study, the sample size was 66. Additional 34 producers were interviewed for precession and certainty purposes. The distribution of the sample over the three production areas in the country (North, middle, and south) was based on the number of broiler farms in each area. The number of farmers to be interviewed was determined by the division of the number of farms in the area on the total number of farms in the country (Relative Importance of the farms in the area). A 47, 40, and 13 farms were interviewed in the Northern, Middle, and Southern areas of production respectively. The formula used to determine the sample size is as follows:

$$
\mathrm{n}=\left[\left(\mathrm{pxqxz} \mathrm{z}^{2}\right) / \mathrm{e}^{2}\right] /\left[\left(\mathrm{Nxe}^{2}\right)+\left(\mathrm{z}^{2} \mathrm{xpxq}\right) /\left(\mathrm{Nxe}^{2}\right)\right]
$$

The sample size which is to be determined is donated by (n).The percentage of the occurrence of the sample is 0.5 and donated by (p) in the formula. The percentage of the sample not to occur is also 0.5 and donated by (q) in the formula. (z) is (1.645) representing the associated standardized score. The allowed error percentage is $(0.10)$ and donated by (e) in the formula. The population from which the sample is selected is 1909 farms, and donated by $(\mathrm{N})$ in the formula. Table 1 shows the distribution of the sample according to the relative importance of the farms.

Another criterion was adopted in the sample selection which is the farm capacity. According to the (Department 
of Statistics, 2010) three categories of farms capacities are dominant in the country. They are less than 5000 birds (small), 5001-50000 birds (medium), and $50001-100000$ birds (large). In the whole country, in the year 2011 there were $390(21 \%), 1381(72 \%)$, and 138 (7\%) small, medium, and large farms respectively (Ministry of Agriculture, 2011). According to this, the interviewed producers were $21 \%, 72 \%$, and $7 \%$ representing small, medium, and large farms respectively in each area. Table 3 shows the total percentage of the interviewed producers according to farm capacity. This means that the total number of the interviewed farmers in North area were 10 or $(47 \times 0.21)$ with small farms, 34 or $(47 \times 0.72)$ with medium farms, and 3 or $(47 \times 0.07)$ with large farms. The total number of the interviewed farmers in Middle area were 8 or $(40 \times 0.21)$ with small farms, 29 or $(40 \times 0.72)$ with medium farms, and 3 or $(40 \times 0.07)$ with large farms. The total number of the interviewed farmers in South area were 3 or $(13 \times 0.21)$ with small farms, 9 or $(13 \times 0.72)$ with medium farms, and 1 or $(13 \times 0.07)$ with large farms. According to this, the total number to be interviewed will be 47, 40, and 13 in the North, Middle, and South areas respectively (Table 2). From these 21, 72 , and 7 will be producers of small, medium, and large farms respectively (Table 3).

Table 1. Distribution of the sample

\begin{tabular}{cccc}
\hline Area of Production & Governorat & No. of Farms & $\begin{array}{c}\text { Percentage to All } \\
\text { Farms }\end{array}$ \\
\hline North & Irbid & 468 & $4.7 \%$ \\
& Jerash & 102 & \\
Mafraq & 238 & \\
\multirow{3}{*}{ Middle } & Ajloun & 085 & $40 \%$ \\
& Amman & 375 & \\
& Madaba & 117 & $13 \%$ \\
Zarqa & 130 & \\
& Balqa & 137 & \\
& Karak & 187 & \\
& Tafeeleh & 033 & \\
& Maan & 010 & \\
& Aqaba & 027 & \\
& 12 & 1909 & \\
\hline
\end{tabular}

Source: Prepared by the researchers based on Ministry of Agriculture 2011, annual report.

Table 2. Total number of interviewed producers according to the area of production

\begin{tabular}{cc}
\hline Area of Production & No. of Farms \\
\hline North & 47 \\
Middle & 40 \\
South & 13 \\
Total & 100 \\
\hline
\end{tabular}

Source: Prepared by the researchers.

Table 3. Total percentage of interviewed producers according to farm capacity

\begin{tabular}{cc}
\hline Area of Production & Percentage of Farms \\
\hline Small & $21 \%$ \\
Medium & $72 \%$ \\
Large & $0.7 \%$ \\
Total & $100 \%$ \\
\hline
\end{tabular}

Source: Prepared by the researchers.

\subsection{Data Collection}

A structured questionnaire was designed to obtain information from respondents regarding socio-economic profiles, total variable costs, revenues, net income, and other related financial items. These items were broken down to their corresponding subtitles. The value of birds, housing costs and equipments were the major considered fixed costs. The feed costs, labor costs and other miscellaneous costs (electricity, medicines ...etc) 
were the variable costs considered in the analysis. The data covered one bird cycle ( $40-45$ days). The study was conducted throughout the period from August 2010 to August 2011. Secondary data sources to achieve the study objectives included the Department of Statistics and the Ministry of Agriculture sources.

\subsection{Data Analysis}

Averages for the costs and revenues were calculated to be considered the core of the analysis when determining of the financial feasibility and other economic considerations. The total fixed, variable costs, and cash flows as well as the total revenues were calculated on one bird cycle basis and then expected for the next nine production cycles. The NPV, IRR, and B/C ratio for the investigated broiler farms were the financial indicators calculated in the study:

- The Net Present Value (NPV): NPV could be calculated as follows:

$$
\mathrm{NPV}=\mathrm{Ri} /(1+\mathrm{i})
$$

where,

$\mathrm{t}=$ time.

$\mathrm{i}=$ discount rate.

$\mathrm{Ri}=$ net cash flow.

- The Internal Rate of Return (IRR): The internal rate of return is useful number to know when you are evaluating an investment. IRR can be mathematically calculated as follows:

$$
\mathrm{CF}_{0}+\frac{\mathrm{CF}_{1}}{(1+\mathrm{r})^{1}}+\frac{\mathrm{CF}_{2}}{(1+\mathrm{r})^{2}}+\frac{\mathrm{CF}_{3}}{(1+\mathrm{r})^{3}}+\frac{\mathrm{CF}_{4}}{(1+\mathrm{r})^{4}}=0
$$

Here CF is the cash flow in the specific period (the last period being $n$ ) and $r$ is IRR to be calculated. IRR is the discounted rate below which an investment results in a positive NPV. It is often assumed that the higher IRR is the better and the more profitable investment (Baker, 2000).

- B/C ratio: The ratio of total value of benefits to the total value of the costs is the $\mathrm{b} / \mathrm{c}$ ratio. $\mathrm{A} \mathrm{B} / \mathrm{C}$ ratio greater than or equal to one is the reliable measurement to accept the investment.

\section{Results and Discussion}

Costs, returns and cash flows under each investigated farm category were determined for ten production cycles. From these three financial items the required financial indicators were computed. Tables $4-6$ show costs and returns for small size broiler farm (2500 birds; as average), medium size broiler farm (27500 birds; as average) and large size broiler farm (75000 birds; as average). In order to judge the economic status for each of the three investigated production capacities, the NPV, IRR and the B/C ratio for each production capacity were calculated, assuming 10 cycles project period. Tables 7 - 9 show the costs, returns and cash flows of the three production capacities for a period of 10 production cycles, assuming that the costs increase by $1 \%$ and the returns increase by $2 \%$ for each production cycle based on market conditions. The discount rate of 0.08 was used when calculating the NPV values. Table 10 shows the values of the three financial indicators used to conduct the economic comparison among the three investigated production capacities.

Table 4. Costs, returns for small size broiler farm (2500 birds; as average)

\begin{tabular}{lc}
\hline \multicolumn{1}{c}{ Item } & JD \\
\hline Housing Cost & 5000 \\
Labor Cost & 350 \\
Total Fixed Costs & 5350 \\
House Preparation (Litter...) Cost & 250 \\
Vaccination and Veterinary Cost & 100 \\
Feed (445 jd/ton) Cost & 4450 \\
Other Costs (Electricity, water, Cleaning \& Sanitizing ....) & 500 \\
Total Variable Costs & 5300 \\
Returns after assuming 5\% mortality and average wt. of $1.7 \mathrm{~kg} / \mathrm{bird}(1.30 \mathrm{JD} / \mathrm{kg})$ & 5249 \\
\hline
\end{tabular}

Source: field survey. 
Table 5. Costs, returns for medium size broiler farm (27500 birds; as average)

\begin{tabular}{lc}
\hline \multicolumn{1}{c}{ Item } & JD \\
\hline Housing Cost & 4000 \\
Labor Cost & 1000 \\
Total Fixed Costs & 41000 \\
House Preparation (Litter...) Cost & 500 \\
Vaccination and Veterinary Cost & 300 \\
Feed (445 jd/ton) Cost & 48950 \\
Other Costs (Electricity, water, Cleaning \& Sanitizing ....) & 1500 \\
Total Variable Costs & 51250 \\
Returns after assuming 5\% mortality and average wt. of $1.7 \mathrm{~kg} / \mathrm{bird}(1.30 \mathrm{JD} / \mathrm{kg})$ & 57736 \\
\hline
\end{tabular}

Source: field survey.

Table 6. Costs, returns for large size broiler farm (75000 birds; as average)

\begin{tabular}{lc}
\hline \multicolumn{1}{c}{ Item } & JD \\
\hline Housing Cost & 90000 \\
Labor Cost & 2500 \\
Total Fixed Costs & 92500 \\
House Preparation (Litter...) Cost & 3000 \\
Vaccination and Veterinary Cost & 1000 \\
Feed (445 jd/ton) Cost & 133500 \\
Other Costs (Electricity, water, Cleaning \& Sanitizing ....) & 6000 \\
Total Variable Costs & 143500 \\
Returns after assuming 5\% mortality and average wt. of $1.7 \mathrm{~kg} / \mathrm{bird}(1.30 \mathrm{JD} / \mathrm{kg})$ & 157463 \\
\hline
\end{tabular}

Table 7. Costs, returns, and cash flow for small size broiler farm (2500 birds; as average)

\begin{tabular}{cccccc}
\hline $\begin{array}{c}\text { Production } \\
\text { Cycle }\end{array}$ & $\begin{array}{c}\text { Total Fixed } \\
\text { Costs (JDs) }\end{array}$ & $\begin{array}{c}\text { Total Variable } \\
\text { Cost (JDs) }\end{array}$ & $\begin{array}{c}\text { Total Costs } \\
\text { (JDs) }\end{array}$ & Returns (JDs) & $\begin{array}{c}\text { Cash } \\
\text { Flow(JDs) }\end{array}$ \\
\hline 1 & 5350 & 5300 & 10650 & 5429 & -5401 \\
2 & & 5353 & 5353 & 5354 & 0001 \\
3 & & 5406.5 & 5406.5 & 5461.1 & 054.6 \\
4 & 5460.5 & 5460.6 & 5570.3 & 109.7 \\
5 & & 5515.2 & 5515.2 & 5681.7 & 166.5 \\
6 & 5570.4 & 5570.4 & 5795.3 & 224.9 \\
7 & & 5626.1 & 5626.1 & 5911.2 & 285.1 \\
8 & & 5682.4 & 5682.4 & 6029.4 & 374.0 \\
9 & & 5739.2 & 5739.2 & 6150.0 & 410.8 \\
10 & & 5796.6 & 5796.6 & 6273.0 & 476.4 \\
\hline
\end{tabular}

Source: Calculated by the researchers.

Table 8. Costs, returns, and cash flow for medium size broiler farm (27500 birds; as average)

\begin{tabular}{cccccc}
\hline $\begin{array}{c}\text { Production } \\
\text { Cycle }\end{array}$ & $\begin{array}{c}\text { Total Fixed } \\
\text { Costs (JDs) }\end{array}$ & $\begin{array}{c}\text { Total Variable } \\
\text { Cost (JDs) }\end{array}$ & $\begin{array}{c}\text { Total Costs } \\
\text { (JDs) }\end{array}$ & Returns (JDs) & $\begin{array}{c}\text { Cash } \\
\text { Flow(JDs) }\end{array}$ \\
\hline 1 & 41000 & 51250 & 92250 & 57736 & -34514 \\
2 & & 51762.5 & 51762.5 & 58890.7 & 7128.2 \\
3 & & 52280.1 & 52280.1 & 60068.5 & 7788.4 \\
4 & & 52802.9 & 52802.9 & 61269.9 & 8467.0 \\
5 & & 53330.9 & 53330.9 & 62494.4 & 9163.5 \\
6 & & 53864.2 & 53864.2 & 63744.3 & 9880.1 \\
7 & & 54402.8 & 54402.8 & 65019.2 & 10616.4 \\
8 & & 54946.8 & 54946.8 & 66319.6 & 11372.8 \\
9 & & 55496.3 & 55496.3 & 67646.0 & 12149.7 \\
10 & & 56051.3 & 56051.3 & 68998.9 & 12947.6 \\
\hline
\end{tabular}

Source: Calculated by the researchers. 
Table 9. Costs, returns, and cash flow for large size broiler farm (75000 birds; as average)

\begin{tabular}{cccccc}
\hline $\begin{array}{c}\text { Production } \\
\text { Cycle }\end{array}$ & $\begin{array}{c}\text { Total Fixed } \\
\text { Costs (JDs) }\end{array}$ & $\begin{array}{c}\text { Total Variable } \\
\text { Cost (JDs) }\end{array}$ & $\begin{array}{c}\text { Total Costs } \\
\text { (JDs) }\end{array}$ & Returns (JDs) & $\begin{array}{c}\text { Cash } \\
\text { Flow(JDs) }\end{array}$ \\
\hline 1 & 92500 & 143500 & 236000 & 157463 & -78537 \\
2 & & 144935 & 144935 & 160612.3 & 15677.3 \\
3 & & 146384.4 & 146384.4 & 163824.5 & 17440.1 \\
4 & & 147848.2 & 147848.2 & 167101.0 & 19252.8 \\
5 & & 149326.7 & 149326.7 & 170443.0 & 21206.3 \\
6 & & 150819.9 & 150819.9 & 173851.9 & 23032.0 \\
7 & & 152328.1 & 152328.1 & 177328.9 & 25000.8 \\
8 & & 153851.4 & 153851.4 & 180875.5 & 27024.1 \\
9 & & 155389.9 & 155389.9 & 184493.0 & 29103.1 \\
10 & & 156943.8 & 156943.8 & 188182.8 & 31239.0 \\
\hline
\end{tabular}

Source: Calculated by the researchers.

Table 10. Values of the financial indicators used in the study

\begin{tabular}{ccc}
\hline Farm Size & Indicator & The Value of the Indicator \\
\hline Small & NPV (JDs) & -3841.1 \\
& IRR (\%) & -12.8 \\
& B/C & 0.91 \\
Medium & NPV (JDs) & 23436.8 \\
& IRR (\%) & 21.7 \\
& B/C & 1.06 \\
Large & NPV (JDs) & 55880.4 \\
& IRR (\%) & 22.1 \\
& B/C & 1.05 \\
\hline
\end{tabular}

Source: Field survey.

Table 10 shows that the magnitudes of the NPV for both the medium and the large size farms were positive and acceptable. NPV for these farms were 23437 and 55880 JDs respectively. For the small farms the NPV value was negative and low (- 3841) indicating non viable type of business compared to the other two capacities. The IRR value for this farm size confirmed this result (IRR was $-12.8 \%$ ). This means that each money unit invested in these farms will cause a loss of 12.8 units. No returns are expected. On the other hand each money unit invested medium and large farms will provide returns higher with about $22 \%$ above the costs paid which means that these capacities are profitable compared to the small size farms. The $\mathrm{B} / \mathrm{C}$ ratio was higher than one for both the medium and the large size farms. This result indicated that the two capacities were viable. The benefits of the two capacities outweighed the actual costs that went in the project. The payback was 1.06 times the costs for both capacities, meaning that for every unit of cost the project will get 1.06 units of gain.

\section{Conclusions}

The values of financial indicators used in this study indicated that adopting the medium and large size of farms for broiler production will be encouraging, profitable and viable. The NPV for both sizes were positive, high, and acceptable. The IRR and B/c ratio values for these two sizes were also economically accepted. Economies of size are the main reason for high profitability of the large farms compared to small farms. Lower feed costs due to lower feed consumption and efficient feed conversion lower feed consumption and better feed efficiency ratios with larger farm size. The results of this study revealed that with the increase of farm size the production costs for each raised bird are lowered, which means that higher returns are earned. Profitability of the small farms could be enhanced by the presence of proper strategies to decrease production costs and to increase income. Feed expenses for the flock in this type of farms should be minimal.

\section{References}

Areerat, T., Hiroshi, K., Kamol, N., \& Yamauchi, K. (2012). Production Efficiency of Broiler Farming in Thailand: A Stochastic Frontier Approach. Journal of Agricultural Science, 4(12), 221-231.

Ascott, E. (2006). Benefit cost analysis of wonder world drive overpass in San Marcos. Master dissertation, Texas Applied Research Project. Texas State University. Retrieved from 
https://digital.library.txstate.edu/bitstream/handle/10877/3783/fulltext.pdf?sequence=1

Baker, S. L. (2000). Perils of the internal rate of return. South Carolina University. Retrieved from http://hspm.sph.sc.edu/COURSES/ECON/invest/invest.html

Barnett, B. J., Black, J. R., Hu, Y., \& Forthcoming, J. R. S. (2005). Is area-yield insurance competitive with farm-yield insurance. Journal of Agricultural and Resource Economics, 30(2), 285-301.

Bent, F., Mette, K., Holm, S., \& Buhl, S. L. (2002). Underestimating costs in public works projects: Error or lie. Journal of American Planning Association, 68(3), 279-295.

Beutler, A. (2007). Introduction to Poultry Production in Saskatchewan. University of Saskatchewan, Saskatoon, Saskatchewan. Retrieved from http://www.agriculture.gov.sk.ca/

Boardman, A. E., Greenberg, D. H., Vining, A. R., \& Weimer, D. L. (2001). Cost-Benefit Analysis: Concepts and Practice (2nd ed.). Prentice Hall Publishers.

Bruce, J. F. (2003). Investment Performance Measurement. New York: Wiley Press.

Department of Statistics (DOS), Jordan. (2011). Yearly Statistics.

Esteghamati, H. Z., Hosseini, S. A., Tabrizi, H. R. M., Palizdar, M. H., \& Meimandipour, A. (2012). Nutritional management of broiler rearing farms in Guilan, Iran. International Journal of Agricultural Management and Development, 2(1), 1-9.

Firadus, M. (2010). Feasibility Analyses of Integrated Broiler Production. Media Peternakan Journal, 33(3), 182-187.

Food and Agriculture Organization (FAO) (2008).

Iman, R., \& Behmanesh, R. (2012). Improve Poultry Farm Efficiency in Iran: Using Combination Neural Networks, Decision Trees and Data Envelopment Analysis (DEA). Research Journal of Poultry Sciences, 5(3), 39-49.

Lin, G. C., Nagalingam, I., \& Sev, V. (2000). CIM Justification and Optimization. London: Taylor and Francis.

Ministry of Agriculture (MoA), Jordan. (2010). Annual Report.

Morly, A. (1982). A Guide to Econometric (1st Ed.), Massachusetts. USA: The MIT Press Cambridge.

Najafi, S., Khademolhosseini, N., \& Ahmadauli, O. (2012). Investigation of Energy Efficiency of Broiler Farms in Different Capacity Management Systems. Iranian Journal of Applied Animal Science, 2(2), 185-189.

Orth, K., Robinson, R., \& Hansen, W. (1998). Making more informed decisions in your watershed when dollars aren't enough. IWR Report 98-R-1, US Army Corps of Engineers, Alexandria, Virginia. Retrieved from http://www.iwr.usace.army.mil/docs/iwrreports/98r1.pdf 